$\mathbb{T}$ periodica polytechnica

Civil Engineering

57/2 (2013) 139155

doi: $10.3311 / P P c i .7170$

http://periodicapolytechnica.org/ci

Creative Commons Attribution (i)

RESEARCH ARTICLE

\section{Parameter-refreshed Chaboche model for mild steel cyclic plasticity behaviour}

Viktor Budaházy / László Dunai

Received 2012-06-12, revised 2012-12-27, accepted 2013-03-15

\section{Abstract}

The development of a steel material model in order to follow the cyclic plastic behaviour is essential in seismic design. The authors present an improved Chaboche model for the cyclic mechanical behaviour of structural steel. The model is based on the combination of nonlinear kinematic and multi-linear isotropic hardening with a parameter refreshing method. This model can consider the different physical phenomena of steel bahviour under cyclic loading. The developed model is verified by experimental results; the calculation of model parameters, the effect of the applied constants and the calibration are discussed.

\section{Keywords}

Steel material model · cyclic loading . Chaboche model . cyclic degradation $\cdot$ cyclic plasticity $\cdot$ saturation of Bauschinger effect $\cdot$ ratcheting effects $\cdot$ material model in ANSYS

\section{Viktor Budaházy}

Department of Structural Engineering, Budapest University of Technology and Economics, Múegyetem rkp. 3, H-1111 Budapest, Hungary e-mail: budahazy.viktor@gmail.com

\section{László Dunai}

Department of Structural Engineering, Budapest University of Technology and Economics, Múegyetem rkp. 3, H-1111 Budapest, Hungary

\section{Notation}

Operator

$d X$

$I_{2}$

$\mathbf{X}: \mathbf{Y}$

$\mathbf{X} \cdot \mathbf{Y}, X \cdot Y$

\section{$\mathbf{X}_{\mathrm{i}}$}

$X^{\mathrm{i}}$

$\Delta X$

Coefficient

\begin{tabular}{|c|c|}
\hline$A$ & elongation after fracture \\
\hline$C$ & $\begin{array}{l}\text { initial hardening variable of Frederick-Armstrong } \\
\text { formula }\end{array}$ \\
\hline$J_{k}$ & impact energy \\
\hline$E$ & Young's modulus \\
\hline$E_{T}$ & tangential stiffness of bilinear model \\
\hline$E_{T k}$ & $\begin{array}{l}\text { slope of the } \mathrm{k}^{\text {th }} \text { segment of stress-strain curve in } \\
\text { Besseling model }\end{array}$ \\
\hline$f_{\mathrm{y}, \text { num }}, f_{\mathrm{y}, \text { real }}$ & $\begin{array}{l}\text { numerical and real yielding point in MISO, NLISO and } \\
\text { PRESCOM model }\end{array}$ \\
\hline$H$ & hardening modulus \\
\hline$m_{i}, \tau_{i}, M_{i}$ & $\begin{array}{l}\text { material parameters of Chaboche model with hardening } \\
\text { recovery }\end{array}$ \\
\hline$Q, b$ & material parameters of isotropic hardening \\
\hline$Q_{M}, Q_{0}, \mu$ & $\begin{array}{l}\text { material parameters of Chaboche model with hardening } \\
\text { memory }\end{array}$ \\
\hline$R_{0}, R_{\infty}, b$ & material parameters of Voce hardening \\
\hline$\alpha, \alpha_{L}, \beta$ & material parameters of PRESCOM model \\
\hline$\beta$ & $\begin{array}{l}\text { saturation parameter of Frederick-Armstrong formula (in } \\
\text { PRESCOM model) }\end{array}$ \\
\hline$\varepsilon_{\mathrm{EQW} 2}$ & $\begin{array}{l}\text { relevant strain of PRESCOM model where the cyclic set } \\
\text { is activated }\end{array}$ \\
\hline$\gamma$ & recovery parameter of Frederick-Armstrong formula \\
\hline$v$ & Poisson's ratio \\
\hline$\omega$ & material constant of modified Chaboche model \\
\hline
\end{tabular}

increment of $\mathrm{X}$ variable

second invariant of deviatoric stress tensor $I_{2}(\mathbf{X})=\left(3 \mathbf{X}_{\mathrm{II}}^{\prime}\right)^{1 / 2}$

double contracted product of $\mathbf{X}$ with $\mathbf{Y}$

single contracted product of $\mathbf{X}$ with $\mathbf{Y}$, or simple multiply operator

$\mathrm{i}^{\text {th }}$ element of a vector

$\mathrm{i}^{\text {th }}$ type of $\mathrm{X}$ variable peak to peak amplitude, or peak point of $\mathrm{X}$ X 
Symbol

\begin{tabular}{|c|c|}
\hline$f$ & plasticity criterion function \\
\hline$f_{y}, k$ & yielding stress, yielding point \\
\hline D & elastic material stiffness matrix \\
\hline$N_{\sigma}$ & stress ratio \\
\hline$p$ & accumulated plastic strain \\
\hline$q$ & maximum value of plastic strain range \\
\hline$R$ & isotropic hardening variable \\
\hline $\mathbf{X}$ & tensor variable of kinematic hardening \\
\hline $\mathbf{X}^{\prime}$ & deviatoric tensor of kinematic hardening \\
\hline$\varepsilon_{\mathrm{RPL}}$ & relevant plastic strain, state variable in PRESCOM model \\
\hline$\varepsilon_{k}, \sigma_{\mathrm{k}}$ & $\begin{array}{l}\mathrm{k}^{\text {th }} \text { point of uniaxial stress strain curve, or actual yielding } \\
\text { stress of isotropic hardening }\end{array}$ \\
\hline$\varepsilon_{P L}$ & plastic strain tensor \\
\hline$\varepsilon_{p l}$ & equivalent plastic strain \\
\hline$\varepsilon_{p l, M A X}$ & maximum value of equivalent plastic strain \\
\hline$\varepsilon_{S}$ & $\begin{array}{l}\text { necessary plastic strain for saturation of hardening in } \\
\text { Frederick-Armstrong formula }\end{array}$ \\
\hline$\psi_{k}$ & weight factor of subvolumes \\
\hline$\mu_{k}$ & isotropic hardening rate factor of subvolumes \\
\hline$\sigma$ & stress tensor \\
\hline$\sigma^{\prime}$ & deviatoric stress tensor \\
\hline$\sigma_{\mathrm{yk}}$ & yielding stress of $\mathrm{k}^{\text {th }}$ subvolumes \\
\hline$\sigma_{\text {xa }}$ & $\begin{array}{l}\text { amplitude of peak stress under non-proportional stress } \\
\text { controlled loading }\end{array}$ \\
\hline$\sigma_{\mathrm{xm}}$ & $\begin{array}{l}\text { mean value of stress under non-proportional stress controlled } \\
\text { loading }\end{array}$ \\
\hline$\sigma_{\Delta}$ & $\begin{array}{l}\text { difference between the numerical and real yielding stress (in } \\
\text { PRESCOM model) }\end{array}$ \\
\hline
\end{tabular}

\section{Introduction}

The global ductility of dissipative steel framed structures is a key issue in seismic design. The global behaviour highly depends on the local ductility of structural members and joints under cyclic loading, what can be studied mainly by experiments. Due to the improvement of computational techniques and hardware background the experiments can be performed by cyclic simulations. In the computational analyses the cyclic plasticity behavior of the steel material has significant role on the local ductility of structural members and joints. Despite significant research completed on the cyclic steel material models in the last decades, the behaviour of yielding plateau under cyclic loading is hard to describe. The developed complex cyclic plasticity mild steel models are still only partially adapted in finite element programs. The main purpose of the current research is to develop an efficient material model taking into account the main characteristics of cyclic behaviour of the steel material, and implement it in a finite element program. In the research a model, on the bases of combination of nonlinear kinematic and multi-linear isotropic hardening and dynamic parameter evaluation is developed, in ANSYS finite element environment [1]. The proposed technique, however, is applicable in most large finite element software environments, where nonlinear kinematic hardening and the combination of different material models are supported. The results show that the accuracy of the cyclic simulation can be improved by the proposed model.

\section{Physical features of cyclic steel material behaviour 2.1 General}

The initial behaviour of structural steel is considered as linearly elastic and isotropic. When the material point turns into plastic state, it can be described by the von Mises criterion and normality yield law. The basic requirement is that the plastic deformation and gradient of the plastic potential function point in the same direction. For metals this requirement means that the potential function is equivalent to the yield criterion. Experiences show that metals are able to resist additional loads after the elastic limit is reached. This means in mathematical description, that the ellipsoid of principal stress state is changed during the loading. If the loading is cyclic or arbitrary, the metals show combined hardening, the yield surface dominantly moves with some expansion.

The primary reason behind the observed difference between monotonic and cyclic behaviour is the crystallite structure of the metals. Dislocations and other crystal defects are able to modify the behaviour of ideal metals. The velocity of these defects is in the order of $100 \mathrm{~ms}^{-1}$, and it causes irregular elastic, and plastic behaviour. Despite the origin of the behaviour is essential, this paper focuses only on the visible effects, not dealing with crystallite translations. The most important physical effects are the elastic after-effect, the Bauschinger effect, the memory of loading history, the ratcheting effect and the effect of strain rate [2, 3], which are discussed in the following sections.

\subsection{Bauschinger effect and the disappearance of the yield- ing plateau}

When the steel material subjected to tension beyond its yield strength experiences unloading and then loading continues in the opposite direction, the yield strength under compression is reduced, while increased for tension. The phenomenon is related to the crystal sizes and defects of convenctional structural metals. The Bauschinger effect is produced by two phenomena, as follows:.

1 The stress in the opposite direction may appear at the intersections of crystals which helps the creation of opposite direction crystal defects. Plastic deformations grow from the defects, so slips appear at lower stress levels in the opposite direction, thus the yielding point is reduced.

2 Residual deformations are not caused in all crystallites if the plastic strain is small; the crystallites, which are deformed by the first loading, are oriented to the direction of the stress state. These slipped crystals are directed back into their original position by the non-slipped crystals when the load direction is reversed. These internal forces are added to the stress from the external load, therefore crystal deformations appear 
at a lower external load level in the opposite direction, resulting in a lower yielding point. Under reloading in the original direction, crystal translations are experienced only at stress levels higher than those from initial loading [4].

The extent of the Bauschinger effect is significant and depends on the material. The initial yield stress range is reduced to approximately $50-70 \%$ for structural steel (depending on strength class), which is much higher than for other structural metals e.g. aluminium or stainless steel. The saturation of Bauschinger effect (i.e. the decrease of the yield surface) depends on the maximum plastic strain. The reduction tends to an asymptotic value and it hardly decreases after the maximum plastic strain reaches approximately $1 \%$, depending on the fabric and chemical composition.

Monotonic mild steel material behaviour differs from cyclic behaviour, as observed by several experiments [5, 6]. As crystal slipping increases, the Bauschinger effect saturates and the yielding plateau gradually disappears.

\subsection{Hardening-softening and non-fading memory}

If the strain range (the difference between maximal and minimal strain levels in a uni-directional load path) under cyclic loading is larger than approximately $0.4 \%$, the maximum stress response is greater than produced by virgin monotonic loading and the normalized size of the yield surface is slightly changed at larger strain levels. Before the Bauschinger effect saturates, the size of the yield surface depends only on the maximum values of plastic strain. After saturation of the Bauschinger effect, the elastic range of total stress, however, depends only on the actual strain level. The dependence of steel behaviour on the maximal plastic strain level at small plastic strain ranges implies that the material is of the non-fading memory type.

When the amplitude of cyclic loading is reduced from a large strain range to a smaller one, the initial peak stress of the smaller strain range will be higher than it would be without previously introducing a large amplitude loading. Furthermore, if the loading is continued at the same strain level, the peak stress gradually decreases as if loading at the larger strain level has never happened.

On the other hand, after stabilization of cyclic hardening at a lower strain level, further significant cyclic hardening is still possible when applying a larger deformation. This behaviour cannot be modeled by pure isotropic hardening law with constant hardening rate. For such materials the stress-strain relationship does not depend only on the accumulated plastic strain, but the previous load history is also important [7].

\subsection{Strain rate effect}

The elastic deformation rate is not influenced only by load levels, but also by the rate of loading. In case of poly crystallite metals, if the load is increased slowly, a greater deformation is created at the same stress level compared to rapid loading. Thus rapid loading increases the Young's modulus of the material.
The strain rate has a significant effect on the yielding point under monotonic loading. This effect is less prominent under cyclic loading, because the material is strained in the strain hardening range, therefore in the current research the strain rate effect is not considered.

\section{Chaboche model for cyclic plasticity}

\subsection{Cyclic plasticity models}

Several material models have been developed in the last few decades since the first anisotropic hardening model was published by Mroz [8] in 1967. In the 1970's the bounding surface model was published by Popov and Krieg that can follow the whole cyclic process, with the modification of the hardening modulus [9]. Based on the above research two model families were developed:

1 Multi-surface models (Popov - Petersson type models [10]): the combined hardening phenomenon is controlled between two extreme stages of material behaviour: virgin (or initial) stage and saturated (or fully-developed) stage.

2 Two-surface models (Dafalias - Popov type models [11]): in these models the actual and limit surfaces are defined and the movement of the actual surface is controlled by a hardening function.

The Chaboche model type is a two surface model for describing cyclic metal material behaviour [12]. This model is widely used in engineering calculations and included in several finite element software, such as ANSYS. Motivated by his work, many researchers proposed improved Chaboche models for cyclic metal simulations. Different Chaboche-based material models are collected in this section.

\subsection{Frederick-Armstrong model}

The basis of the Chaboche model is the Frederick-Armstrong model [13]. The hardening equation in this model is described by strain hardening variables. The principle of nonlinear kinematic hardening model is that the loading surface, the limit surface and the current stress state depend on the plastic strain introducing a recall term, called dynamic recovery. The von Mises criterion and a linear function $f_{y}$ of the stress invariant $I_{2}$ is used in case of metals.

The model is described by Prager's equations and the yield criterion can be expressed in the following form:

$$
f=I_{2}(\sigma-\mathbf{X})-k
$$

where $\sigma$ is the stress vector, $k$ is the yielding point, and $\mathbf{X}$ is the hardening variable. The increment of the hardening parameter is the function of the accumulated plastic strain:

$$
\begin{aligned}
& d \mathbf{X}=2 / 3 \cdot C \cdot d \boldsymbol{\varepsilon}_{P L}-\gamma \mathbf{X} d p \text { and } \\
& d p=\left|d \boldsymbol{\varepsilon}_{P L}\right|=\left(2 / 3 d \boldsymbol{\varepsilon}_{P L}: d \boldsymbol{\varepsilon}_{P L}\right)^{1 / 2}
\end{aligned}
$$

where $d \mathbf{X}$ the increment of kinematic hardening tensor, and it is expressed by two parameters, the initial hardening modulus 
$(C)$ and the nonlinear recovery parameter $(\gamma)$ which introduces a fading memory effect of the strain path [14]. The hardening modulus can be expressed as:

$$
H=C-\frac{3}{2} \gamma \mathbf{X}: \frac{\sigma^{\prime}-\mathbf{X}^{\prime}}{k}
$$

The application of the Frederick-Armstrong model is difficult because the parameter calibration requires a complex procedure. There are three ways to calibrate a Frederick-Armstrong model: (i) with monotonic stress-strain curve, (ii) one stabilized hysteresis loop, and (iii) stabilized hysteresis loops of different strain amplitudes. The latter leads to the most accurate procedure, as shown in [14,15]. The model is more accurate than a simple bilinear model and in case of some metals (e.g. titanium alloy, NIMONIC 90 alloy [14]) it is sufficiently accurate. However its disadvantage is that it only shows fading memory effects, but cannot describe the cyclic hardening at the same strain level and the decrease of the yielding plateau experienced in structural steel.

\subsection{Superposition of several kinematic and isotropic mod- els}

A single nonlinear kinematic hardening model cannot describe the cyclic behaviour of structural steel appropriately. The combination of isotropic and kinematic hardening models is necessary to increase the model accuracy. The characteristics of a Frederick-Armstrong model are determined by the $C$ and $\gamma$ values; different value pairs result in different characteristics. Chaboche and Rousselier [16] observed that, the hardening behaviour of the steel material can be better approximated by the sum of different Frederick-Armstrong formulas. They developed the Chaboche model in which several formulas detailed in Eq. (2) are added. The combined criterion is expressed in Eq. (1), where the translation vector of hardening can be expressed as:

$$
\mathbf{X}=\sum_{i=1}^{n} \mathbf{X}_{i} \quad \text { and } \quad d \mathbf{X}_{i}=2 / 3 \cdot C_{i} \cdot d \boldsymbol{\varepsilon}_{P L}-\gamma_{i} \mathbf{X}_{i} d p
$$

The superposition of isotropic hardening on nonlinear kinematic hardening results in a modification of the yield surface by both uniform expansion and translation. Isotropic hardening is controlled by the accumulated plastic strain $(p)$ and the associated thermodynamic force $(R)$ which represents the change in the size of the elastic domain. Eq. (1) can be written in this case is as follows:

$$
f=I_{2}(\sigma-\mathbf{X})-R-k
$$

The value of $R$ can be positive (cyclic hardening) or negative (cyclic softening), but the result of isotropic and kinematic effect must be hardening during the whole load path. The isotropic part of the hardening can be linear, multi-linear or nonlinear. If the hardening is nonlinear, it is advantageous to express isotropic and kinematic hardening in the same form:

$$
d R=b(Q-R) d p
$$

where $Q$ is the asymptotic value in the stabilized hysteresis loops, and $b$ determines the velocity of stabilizing. This model describes the behaviour of cyclic loaded metals more accurately, the isotropic part of the hardening shows non-fading memory effect, but cannot model the yielding plateau and the decrease of initial yielding surface. Therefore it shows significant inaccuracy in case of mild steel, especially in the range of small plastic strains.

\subsection{Modifications of Chaboche model}

The Chaboche model has some general inaccuracy. Overestimates the ratchetting effect, cannot describe the yielding plateau, and cannot describe properly the hardening memory effect. Therefore several modified nonlinear kinematic hardening models have been developed to improve the accuracy. The cyclic hardening phenomenon at the same strain amplitude is relatively slow; it typically takes between ten and one thousand cycles for the loops to stabilize. Therefore, the value of $b$ in Eq. (6) will be in between 50 and 0.5. It is possible to couple isotropic and kinematic hardening by the function $\varphi(p)$ defined in Eq. (7) [17, 18]. A possible choice of $\varphi(p)$ as a function of $R$ is also shown, where $\omega$ is material constant:

$$
\begin{aligned}
& d \mathbf{X}_{i}=2 / 3 \cdot C_{i} \cdot d \boldsymbol{\varepsilon}_{P L}-\gamma_{i} \cdot \varphi(p) \mathbf{X}_{i} d p \text { where } \\
& \varphi(p)=1 /(1+\omega R(p))
\end{aligned}
$$

By this modification the modulus of kinematic hardening becomes the function of isotropic hardening, which results in a more accurate stress-strain relationship, but the decrease of the yielding surface and plateau is still not described.

Another important modification is the hardening memory. Simple nonlinear models describe the hardening with fading memory type. The elimination of the effect of the previous load history can cause inaccuracy in the cyclic stress-strain relationship. Chaboche [19] introduced an additional state variable to account for this problem. Observation of cycles under sequential loading shows that this memory effect can be stored with the maximum plastic strain range $(q)$, so the asymptotic values $Q$ in the isotropic variable $R$ in Eq. (6) are no longer constants, they depend on the maximum strain amplitude. A relationship to consider this effect is shown in Eq. (8):

$$
Q=Q_{M}-\left(Q_{M}-Q_{0}\right) \exp (-2 \mu q)
$$

where $Q_{M}, Q_{0}$ and $\mu$ are three constants. By this modification only the isotropic part of the hardening can show non-fading memory type, which is highly efficient for metals without yielding plateau; such as stainless steel.

Hardening recovery in the function of time generally occurs at high temperature. Chaboche [14,19] used a power function in the recall term acting as a function of time to take this phenomenon into consideration:

$$
d \mathbf{X}_{i}=\frac{2}{3} \cdot C_{i} \cdot d \boldsymbol{\varepsilon}_{P L}-\gamma_{i} \mathbf{X}_{i} d p-\frac{\gamma}{\tau_{i}(T)}\left(\frac{\left\|\mathbf{X}_{i}\right\|}{M_{i}}\right)^{m-1} \mathbf{X}_{i}
$$


where $m_{i}, \tau_{i}, M_{i}$ depend on material type and temperature. Since the change in temperature is negligible during the seismic effect, this modification does not affect the practical accuracy.

\subsection{Summary of Chaboche models}

In this chapter material models based on the Chaboche equations are presented. These models can follow several important characteristics of the cyclic behaviour of steel materials. The models, however, cannot consider the change in the yielding surface and plateau.

To increasing model complexity in general is disadvantageous from the practical applicability point of view, therefore it is important to consider only those physical phenomena that influence global response significantly. The purpose of the current research is to develop a material model which is able to describe all the relevant phenomena, on the basis of the Chaboche model, what can be adopted in numerical applications. The following physical phenomena are found to be significant during model development (in the order of importance): kinematic hardening, Bauschinger effect, decrease of the yielding surface, disappearance of the yielding plateau, plastic creep, and strain memory.

\section{Modelling cyclic steel behaviour in ANSYS finite ele- ment program}

The previously described material models are only partially adopted in finite element programs. The modelling of cyclic steel behaviour in ANSYS software can be done by the models as follows: (i) bilinear model, (ii) multi-linear model, (iii) basic Chaboche model, (iv) NLISO model, (v) MISO model, (vi) PRESCOM model. The models (iv-vi) are developed by the authors. In this chapter these models are introduced and the obtained numerical results are compared for each model by experimental stress-strain plots on the basis of the studies of Meng et al. [5]. Two series of experiments with a total of 50 tests on Q235B and Q345B steel specimens were studied by the authors using several different load protocols. The experimental monotonic and hysteresis behaviour, ductility characteristics and cumulative damage degradation are discussed in the paper in detail. In this paper the calibrations of the different material models were performed using the Q345B experimental results. The most important mechanical properties of the material are shown in Fig. 1 and Table 1

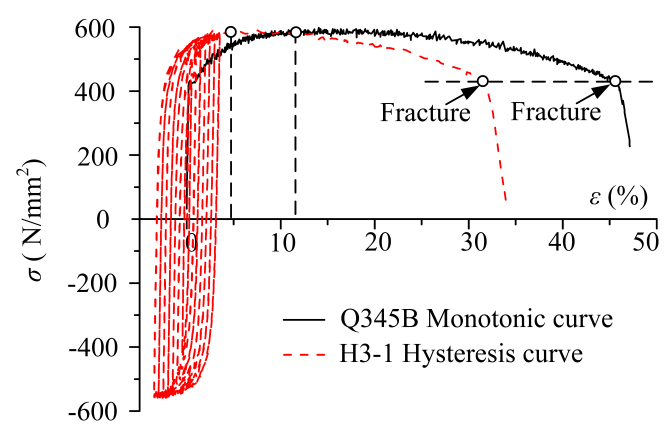

Fig. 1. Monotonic and cyclic behaviour of Q345B [5]
Tab. 1. Mechanical properties of Q34B

\begin{tabular}{ccccc}
\hline$E(\mathrm{MPa})$ & $f_{\mathrm{y}}(\mathrm{MPa})$ & $f_{\mathrm{u}}(\mathrm{MPa})$ & $A(\%)$ & $J_{\mathrm{k}}(\mathrm{J})$ \\
\hline 205000 & 423 & 589 & 24 & 182198207
\end{tabular}

\subsection{Modelling cyclic steel behaviour by bilinear model}

As previously discussed, the isotropic hardening can be used to model the steel material behaviour only under monotonic loading and the bilinear kinematic hardening is the simplest way to model cyclic behaviour. The model is described by Prager's equations and the yield criterion is the same as in the FrederickArmstrong model in Eq. (1). This model is a bilinear kinematic hardening model, in which the kinematic hardening variable $(\mathbf{X})$ is collinear with the plastic strain Eq. (10).

$$
f=I_{2}(\sigma-\mathbf{X})-k \text { where } d \mathbf{X}=2 / 3 \cdot C \cdot d \boldsymbol{\varepsilon}_{P L}
$$

The used yielding law is the von Mises yield criterion. It is independent from the strain rate and temperature. The hardening rate is constant, and it is calibrated by the experimental results using the method of least squares (Table 2). Fig. 2 compares the numerical and experimental results.

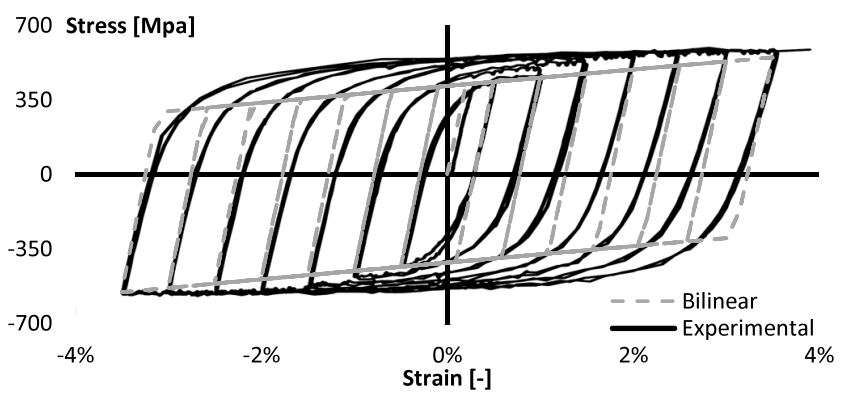

Fig. 2. Cyclic behaviour of bilinear material model

The model takes the Bauschinger effect into account in the simplest possible way. It cannot show the decrease of the yielding surface and does not represent any kind of memory properties. It is inaccurate in case of cycling loading: the hysteresis loops are angled, the value of stress and amount of dissipated energy is less than the actual value; except for small strain levels, where less cyclic hardening is experienced. In spite of the significant inaccuracies in this model, it is widely used in analysis due to its simplicity.

Tab. 2. Material constants of bilinear model

\begin{tabular}{ccc}
\hline$E(\mathrm{MPa})$ & $f_{\mathrm{y}}(\mathrm{MPa})$ & $E_{\mathrm{T}}(\mathrm{MPa})$ \\
\hline 205000 & 423 & 3900 \\
\hline
\end{tabular}

4.2 Modelling cyclic steel behaviour by multi-linear model This material model is a Besseling model [20] and also known as sub-layer or overlay model [21]. It is similar to the piecewise linear kinematic hardening rule and the Mroz [8] model without any notion of surfaces. The theory is based upon the material 
Tab. 3. Stress-strain points of multi-linear model

\begin{tabular}{cccccccc}
\hline$\varepsilon_{\mathrm{k}}(-)$ & $\sigma_{\mathrm{k}}(\mathrm{MPa})$ & $\varepsilon_{\mathrm{k}}(-)$ & $\sigma_{\mathrm{k}}(\mathrm{MPa})$ & $\varepsilon_{\mathrm{k}}(-)$ & $\sigma_{\mathrm{k}}(\mathrm{MPa})$ & $\varepsilon_{\mathrm{k}}(-)$ & $\sigma_{\mathrm{k}}(\mathrm{MPa})$ \\
\hline 0.0020143 & 423.0 & 0.012422 & 508.6 & 0.022657 & 557.9 & 0.03275 & 579.9 \\
\hline 0.004104 & 441.9 & 0.014484 & 521.7 & 0.024684 & 563.7 & 0.03476 & 581.5 \\
\hline 0.006192 & 460.3 & 0.016538 & 533 & 0.026706 & 568.4 & 0.03677 & 582.8 \\
\hline 0.008275 & 477.8 & 0.018585 & 542.8 & 0.02872 & 572.4 & 0.03878 & 583.9 \\
\hline 0.010325 & 494 & 0.020624 & 551 & 0.03074 & 575.3 & 0.04078 & 584.7 \\
\hline
\end{tabular}

which is macroscopically homogeneous, but inhomogeneous on microscopic scale. In this material the plastic deformation will occur at certain points and will spread in subsequent loading over the whole volume. This phenomenon is composed of various portions (or sub-volumes), all is given to the same total strain, but each portion has different yielding strength. Although the behaviour of sub-volumes show isotropic hardening the different elastic limit of portions cause the hardening of volume to be anisotropic.

This model is defined by several points of the uniaxial stressstrain relationship $\left(\varepsilon_{\mathrm{k}}, \sigma_{\mathrm{k}}\right)$, when sufficient segments are defined, angularity of the model is reduced (Fig. 3. Table 3). The yield stress for each sub-volumes is given by Eq. (11):

$$
\sigma_{y k}=\frac{1}{2(1+v)}\left(3 E \varepsilon_{k}-(1-2 v) \sigma_{k}\right)
$$

The relation between the stress and strain can be expressed as follows:

$$
\begin{aligned}
& d \sigma=\mathbf{D}\left\{1-\sum_{1}^{N} \psi_{k}\left(1-\mu_{k}\right)\right\} d \varepsilon \text { where } \\
& \sum_{1}^{N} \psi_{k}=1 \text { and } \psi_{k}=\frac{E-E_{T k}}{E-\frac{1-2 v}{3} E_{T k}}-\sum_{1}^{k-1} \psi_{i}
\end{aligned}
$$

where $\psi_{\mathrm{k}}$ is the weight factor of sub-volumes and $\mu_{\mathrm{k}}$ is defined as constant. In ANSYS $\mu_{\mathrm{k}}=0$, therefore each subvolumes are perfectly plastic and after the last point is defined, no further hardening is considered.

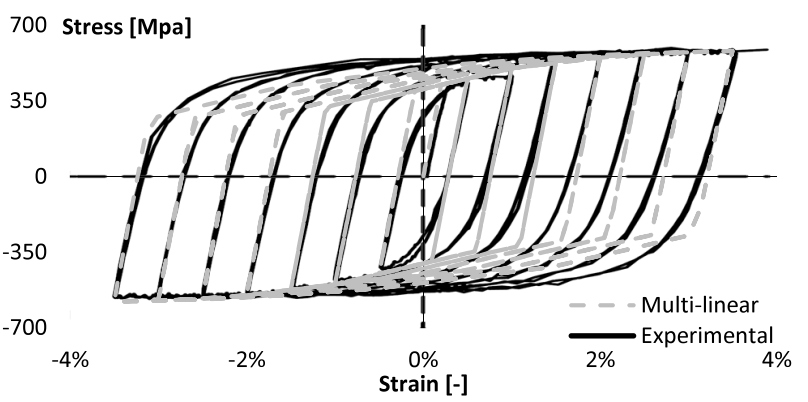

Fig. 3. Cyclic behaviour of multi-linear model

This model approximates the experimental result better, but the difference between the numerical and experimental curves is still significant. The calculated hysteresis loops are still angled and they show less energy dissipation and lower stress levels than the test results.

\subsection{Modelling cyclic steel behaviour by the basic Chaboche model}

The main difference between a Besseling and Chaboche model is the state variable. The Besseling model uses the function of strain (or plastic strain) while the Chaboche model's state variable is the accumulated plastic strain. If the number of sublayers is satisfactory, a given nonlinear stress-strain curve can be approximated by linear sections. However, since the state variable of the Besseling model cannot model the fading memory type, it approximates arbitrary loading histories with inferior accuracy. This phenomenon can be seen by comparing Figs. 3 and 4/a.

The Chaboche material model can combine several FrederickAmstrong formula. In the simple case, only one FrederickAmstrong formula is used, therefore in this model the hardening behaviour is the same as given in Eq. (2). Parameters of the basic Chaboche model can be determined more accurately, using several stabilized hysteresis loops (Table 4). The details of calibration are presented in [19,22] and illustrated in Fig. 4/,b.

Tab. 4. Material constants of the basic Chaboche model

\begin{tabular}{cccc}
\hline$E(\mathrm{MPa})$ & $f_{\mathrm{y}}(\mathrm{MPa})$ & $C(\mathrm{MPa})$ & $\gamma(-)$ \\
\hline 205000 & 429 & 19140 & 116 \\
\hline
\end{tabular}

\subsection{Modelling cyclic steel behaviour by the NLISO model}

The NLISO model (Chaboche model combined with NonLinear ISOtrope hardening) is developed to increase the accuracy of the basic Chaboche model. In this model three Frederick-Armstrong formulas are used and combined with nonlinear isotropic hardening, developed by Voce [22]. The hardening variable (X) is expressed in Eq. (4), and the yielding law is given in Eq. (5) where the $R$ variable is specified by the following form:

$$
R=R_{0} \cdot \varepsilon_{p l}+R_{\infty}\left(1-e^{-b \varepsilon_{p l}}\right)
$$

$R_{\mathrm{o}}, R_{\infty}, b$ characterize the isotropic hardening behaviour of materials detailed in Table $5 R_{\mathrm{o}}+R_{\infty}$ are the initial isotropic hardening modulus, $R_{\mathrm{O}}$ is the asymptotic hardening and b controls the decrease of hardening in the function of equivalent plastic strain. This model describes the stress-strain curves more accurately: its loops are less angled, isotropic hardening is taken into consideration and description of the ratcheting effect is satisfactory, as shown in Fig. 5. The used Frederic-Armstrong formulas are in Eq. (2), the used material constants are in Table 5 

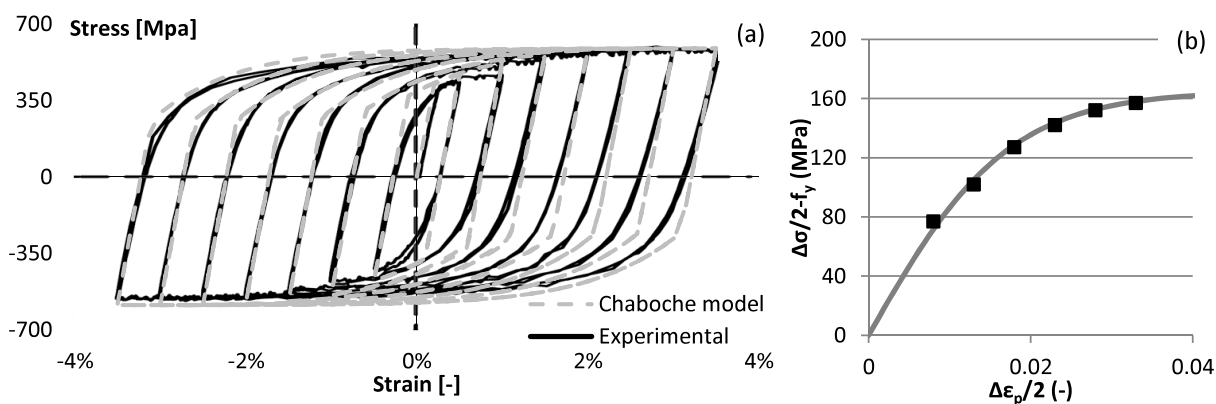

Fig. 4. Cyclic behaviour of the basic Chaboche model (a), curve fitting by the method of least squares of, using 6 stabilized hysteretic loops (b)

The decreasing of the yielding surface is taken into consideration by lower constant yielding stress $\left(f_{\mathrm{y}, \text { num }}\right)$, instead of its saturation tendency (Table 5). By this modification the model describes the cyclic behaviour at large plastic strain levels appropriately. Under monotonic loading and at small plastic strain levels, however, to follow the mild steel behaviour is completely different. Since its parameters are calibrated by saturated steel behaviour, the model shows some inaccuracy: if the loading level is smaller than the plastic strain corresponds to saturation of Bauschinger effect $(0.5-1 \%)$ the model shows lower stressstrain values than it is created.

Tab. 5. Parameters of the NLISO model

\begin{tabular}{|c|c|c|c|c|c|c|}
\hline \multirow{3}{*}{\multicolumn{2}{|c|}{$\begin{array}{c}f_{\mathrm{y}, \text { num }}=260 \mathrm{MPa} \\
f_{\mathrm{y}, \text { real }}=423 \mathrm{MPa} \\
E=205000 \mathrm{MPa}\end{array}$}} & \multirow{2}{*}{\multicolumn{3}{|c|}{$\begin{array}{l}\text { Kinematic hardening } \\
\text { Chaboche models }\end{array}$}} & \multirow{3}{*}{\multicolumn{2}{|c|}{$\begin{array}{l}\text { Isotropic hardening } \\
\text { Voce model } \\
\text { parameters }\end{array}$}} \\
\hline & & & & & & \\
\hline & & C & $\gamma$ & $\Delta \sigma$ & & \\
\hline \multirow{3}{*}{ Formula \# } & I. & 100000 & 1500 & 133 & $R_{0}$ & 50 \\
\hline & II. & 7500 & 375 & 20 & $R_{\infty}$ & 30 \\
\hline & III. & 400 & 0 & - & $b$ & 50 \\
\hline
\end{tabular}

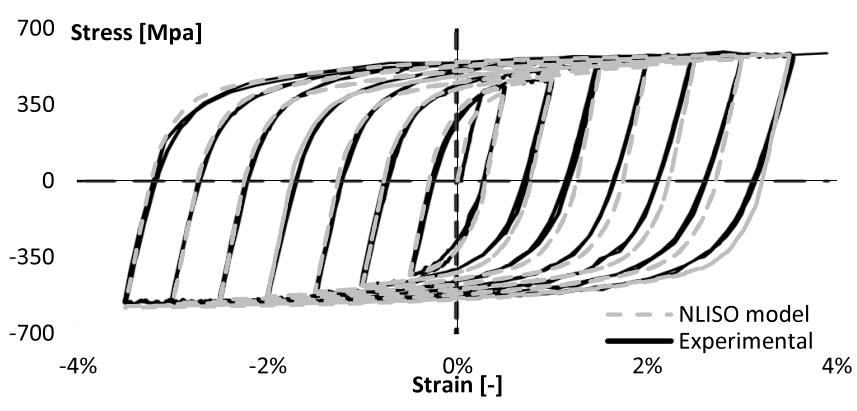

Fig. 5. Cyclic behaviour of the NLISO model

\subsection{Modelling cyclic steel behaviour by the MISO model}

The MISO model (Chaboche model combined with Multilinear ISOtrope hardening) is developed to describe the difference between monotonic and cyclic steel behaviour into consideration better. Monotonic and cyclic behaviour are difficult to follow by the same equations and material constants, therefore a separate set of monotonic and cyclic parameters should be created. Each parameter set consist a Chaboche model with five Frederick-Armstrong formulas, and a multi-linear isotropic hardening, as shown in Table 6 The difference between the two parameter sets is the isotropic part of the hardening, but the
Chaboche model is the same. The yielding plateau of monotonic steel is described by a special superposition of hardening models: combination of kinematic hardening with multi-linear isotropic softening results in constant stress, the decrease of yielding surface in the plateau region and hardening after the plateau. This approach gives accurate results for monotonic loading.

In this case the Eq. (1) is modified in the following form:

$$
f=I_{2}(\sigma-\mathbf{X})-\sigma_{k}
$$

where $\sigma_{\mathrm{k}}$ can be determined directly from the equivalent plastic strain. Fig. 6 shows the isotropic hardening behaviour, the kinematic hardening behaviour and the sum of them.

The decrease of $\sigma_{\mathrm{k}}$ follows the decrease of the yielding surface at the plateau zone. In the numerical model the $f_{\mathrm{y}, \text { num }}$ yielding stress is defined for Chaboche and isotropic model. The real yielding stress is calculated as the sum of isotropic and kinematic hardening.

The monotonic parameter set is used at the beginning of the loading. At the first occurrence of unloading if the yielding point is reached, the cyclic parameter set is applied (Table 6). By this configuration the MISO model can describe the difference between monotonic and cyclic behavior, as shown in Fig.7

If the strain range is larger than approximately $0.4 \%$, the cyclic (or monotonic of saturated steel) stress response is greater than the response of virgin monotonic loading. If the loading do not reach this strain level, the stress-strain response of steel is bigger than the cyclic steel behaviour. In the MISO model there are two considered state variables, which control the switch of parameter set: (i) equivalent plastic strain, (ii) equivalent stress. If the yielding stress is used as state variable and the first unloading occurs at a small plastic strain level (the maximum deformation is less than $0.4 \%$ ), the cyclic parameter set of the MISO model produces lower stresses than the experiments. Furthermore, the dislocation of the yield surface is different in the two configurations, which leads to discontinuity in the stress-strain curve, as it can be seen in Fig. 8/a.

If the switching to the cyclic parameter set is controlled by the maximal equivalent strain level instead of the yield stress, the experienced discontinuity of the stress-strain curve can be avoided but the combination of isotropic softening and kinematic hardening leads to the cyclic decrease of the yield surface. 


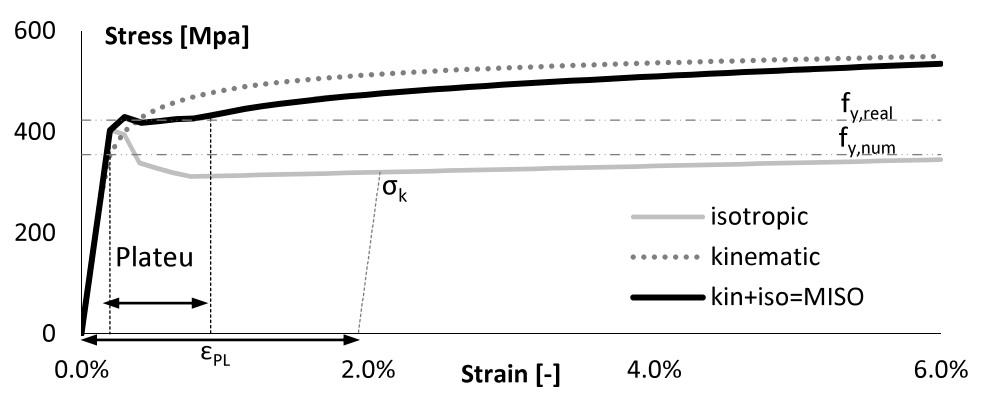

Fig. 6. Monotonic behaviour of special isotropic hardening, kinematic hardening and the MISO model

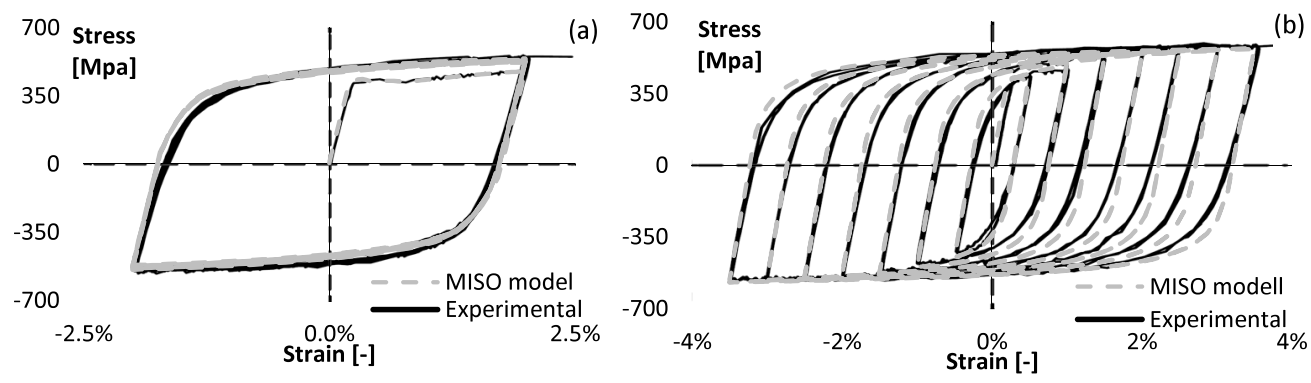

Fig. 7. Cyclic behaviour of MISO model under constant amplitude of loading (a) and increasing loading (b)

(a)

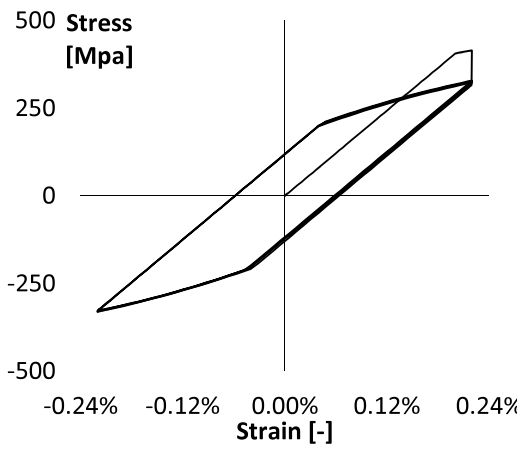

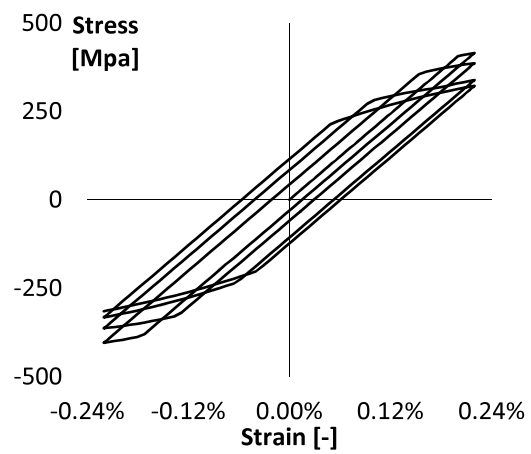

Fig. 8. Inaccuracy of the MISO model at small plastic strain range controlled by yield stress (a), and controlled by maximal plastic strain (b)

Tab. 6. Parameters of MISO model

\begin{tabular}{cccccccccc}
\hline$f_{\mathrm{y}, \text { num }}=335 \mathrm{MPa}$ & \multicolumn{4}{c}{ Monotonic set } & \multicolumn{4}{c}{ Cyclic set } \\
$f_{\mathrm{y}, \text { real }}=423 \mathrm{MPa}$ & \multicolumn{2}{c}{ Chaboche models } & \multicolumn{2}{c}{ Multi-linear } & \multicolumn{2}{c}{ Chaboche models } & Multi-linear \\
\hline$E=205000 \mathrm{MPa}$ & $C$ & $\gamma$ & $\varepsilon_{\mathrm{pl}}[-]$ & $\sigma$ & $C$ & $\gamma$ & $\varepsilon_{\mathrm{pl}}[-]$ & $\sigma$ \\
\hline & I. & 75000 & 1500 & 0.00200 & 328 & 75000 & 1500 & 0.002 & 328 \\
\cline { 2 - 12 } Formula \# $\#$ & II. & 21000 & 375 & 0.00235 & 315 & 21000 & 375 & 0.05 & 339 \\
\cline { 2 - 12 } & III. & 7000 & 120 & 0.00610 & 288 & 7000 & 120 & 0.1 & 355 \\
\cline { 2 - 11 } & IV. & 1100 & 25 & 0.01 & 355 & 1100 & 25 & 4.5 & 450 \\
\cline { 2 - 10 } & V. & 300 & 0 & 4.5 & 45 & 300 & 0 & & \\
\hline
\end{tabular}


Therefore, the model is still inaccurate in the zone of small plastic strains (Fig. 8/b).

This model approximates the experimental result in general accurately, but if the plastic strain range is small, parameters of the MISO model (either monotonic or cyclic) cannot follow the yield surface and the transition from exclusively monotonic to cyclic behaviour. This is why the saturation of the Bauschinger effect and the decrease of the yielding plateau require transitional states. The parameter refreshing method is developed to extend the accuracy of the MISO model to the small plastic strain range, too.

\section{Chaboche model with dynamically updated parame- ters}

On the basis of the above experiences by the different Chaboche models an improvement on the MISO model is completed. A dynamically updated material model (called PRESCOM - Parameter REfreshed and Strain COntrolled combined Chaboche Model with isotropic hardening) is developed. It consists of a Chaboche model with five superposed FrederickArmstrong formula and a multi-linear isotropic hardening. The model details, parameter calibration and verification are presented in this chapter.

\subsection{Strategy of development}

The presented MISO model is able to describe steel behaviour under monotonic, and large amplitude cyclic loading, although the cyclic and monotonic parameter set with constant parameters cannot follow the change in material behaviour. Therefore, a third parameter set is defined to describe the transitional state, from monotonic to cyclic behaviour. In this state a function is used to calculate model parameters during the loading. Two variables are examined considering experimental results: (i) the maximum value of equivalent plastic strain $\left(\varepsilon_{p l, M A X}\right)$, and (ii) the maximum value of strain range $(q)$. Although saturation of the Bauschinger effect and the decrease of the yield surface depend on the maximum plastic strain, the stress-strain relationship at the small strain range is also influenced by the previously experienced maximum strain range, as shown in Fig.9 The optimal approximation is obtained when the maximum of $\varepsilon_{p l, M A X}$ and $q$ is used as state variable in the model:

$$
\varepsilon_{R P L}=\max \left(\varepsilon_{p l . M A X}, q\right)
$$

where $\varepsilon_{R P L}$ is called the relevant plastic strain.

The change of the material behaviour can appear after each load steps. In this case a load step means the difference in the loading history between two points, where the inner point of yielding surface is reached. This phenomenon is described by the stress ratio, shown in Eq. 16. When $N_{\sigma}$ is less than one the stress state is elastic, else yielding occurs. $\sigma_{k}$ depends on the yielding condition and $\sigma_{\mathrm{e}}$ is the equivalent stress evaluated using the deviatoric stress tensor.

$$
N_{\sigma}=\frac{\sigma_{e}}{\sigma_{k}}
$$

\subsection{Calculation of the dynamic model parameters}

The algorithm of the dynamic model parameter calculation can be seen in Fig. 10. At the beginning of the loading the monotonic parameter set is used for every steel element in the dissipative zones of the structure. After a load step the maximum value of equivalent plastic strain is evaluated, and the material model constants are updated by the following way: if the value of the plastic strain is zero, the parameter set is kept monotonic, if it is greater than a pre-defined limit $\left(\varepsilon_{E Q W 2}\right)$, the cyclic parameter set is loaded and if it is in between 0 and $\varepsilon_{E Q W 2}$, the behaviour can be characterized by the transitional parameters, using the function of relevant plastic strain given in Section 5.1. The maximal equivalent plastic strain and the maximum strain range are evaluated after each load step. If the new relevant strain is greater than the previous one, the parameter set of the model is updated using the above procedure. If the relevant strain does not change, the parameters remain the same. This procedure builds the hardening memory effect at the critical range of small plastic strains into the material model using the relevant plastic strain to describe the change in the material behaviour. The most accurate solution is given if this procedure is performed on the integration point level of the numerical discretization. Note that in the ANSYS environment the evaluation and the material setting of the presented PRESCOM model are completed on element level instead of integration point level.

The PRESCOM model uses yield stress $\left(f_{\mathrm{y}, \text { num }}\right)$, which refers to the decreased yield surface, similarly to the MISO model. The yield surface gradually decreases after each consecutive load cycle depending on the maximal strain level reached during the given cycle. In spite of this yield surface reduction, the stress at the maximal strain level cannot decrease during cyclic loading. Therefore, the hardening rate of the model has to be increased in parallel with the shrinkage of the yield surface, as shown in Fig. 11. At the transitional range the model parameters are updated to reach the appropriate stress level when the strain amplitudes reach the maximum.

The material model consists of Chaboche models with five different formulas, as detailed in Table 7. The PRESCOM model's initial hardening behaviour primarily depends on the Frederick-Armstrong formula with large $C$ and $\gamma$ parameters. The maximum shifting of loading surface is given by $C / \gamma[14]$. The shifting value is fixed in Fig. 12. Applying large $C$ and $\gamma$ value results in significant initial hardening, but the whole hardening saturates already at a small plastic strain level $\left(\varepsilon_{\mathrm{S}}\right.$ in Fig. 12). While Eq. (2) produces larger shifting of yielding surface than the initial hardening modulus, the initial hardening modulus is used. The combined isotropic hardening is relatively small and the Frederick-Armstrong formulas with small $C$ values has relatively small effect at this strain rate (Model 4 in Fig. 12). The first Frederic-Armstrong formula of PRESCOM model governs the small plastic strain behaviour, the second and third govern both small and large plastic stress-strain relation- 


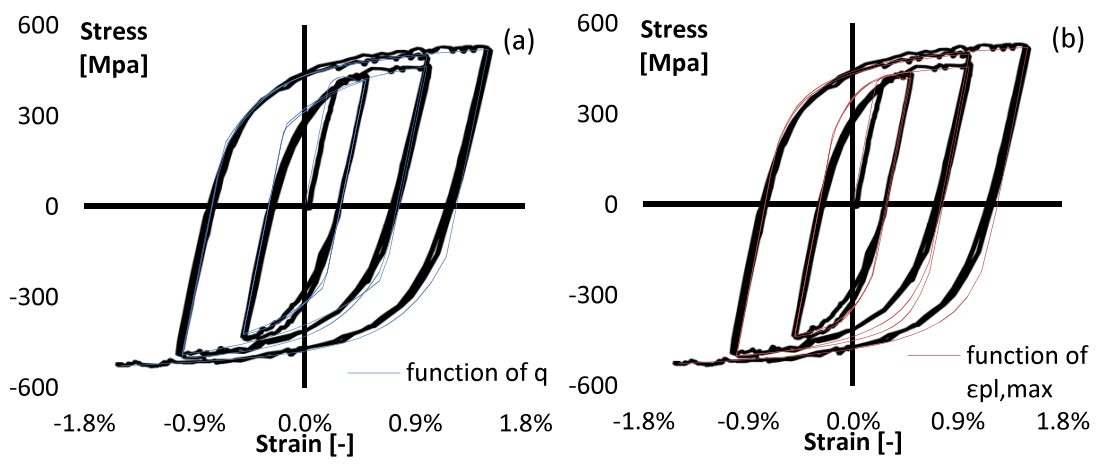

Fig. 9. Illustration of the PRESCOM model with two variables: function of $q$ (a) function of the maximum value of equivalent plastic strain (b)

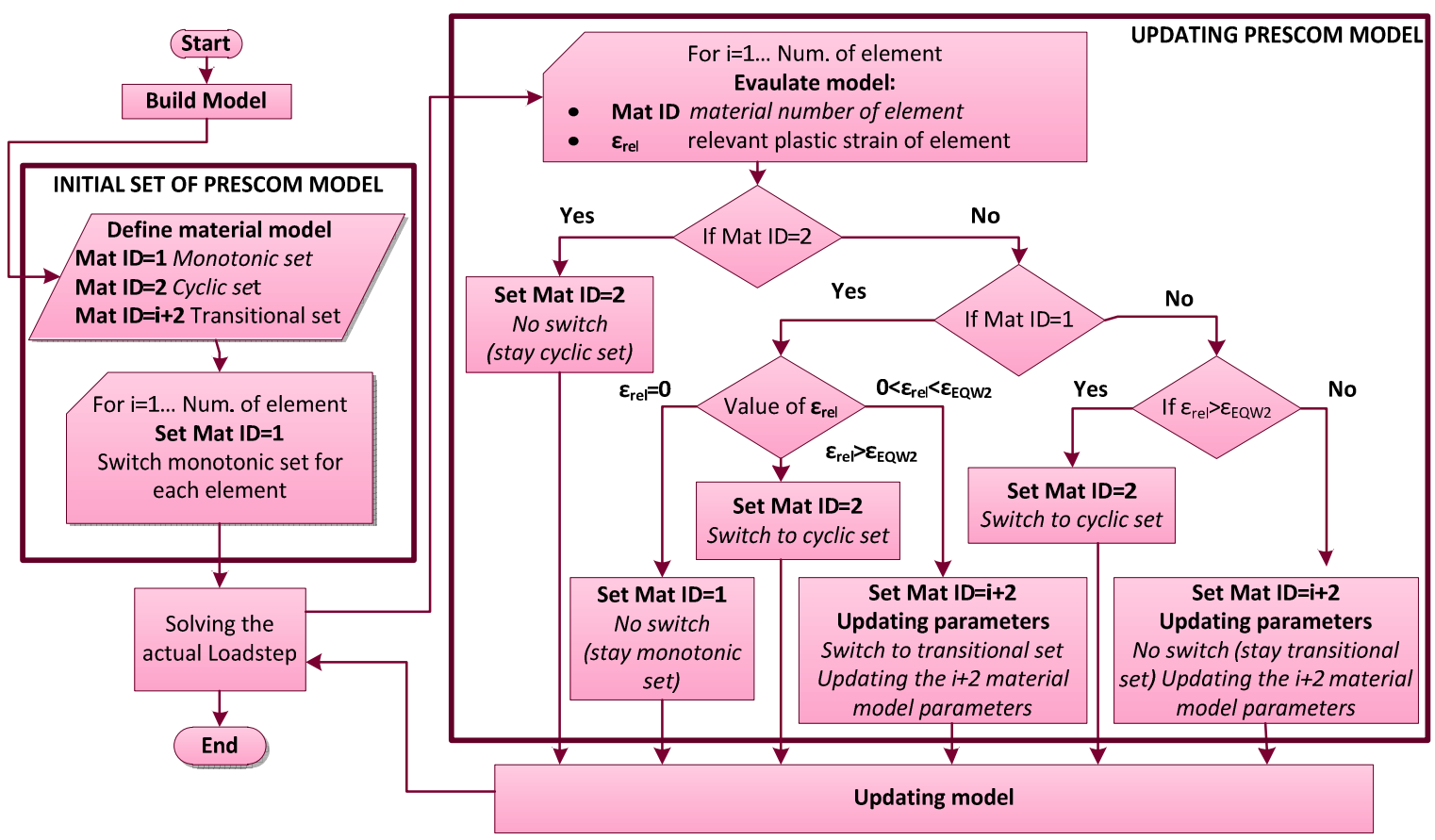

Fig. 10. Algorithm of the parameter updating in the PRESCOM model

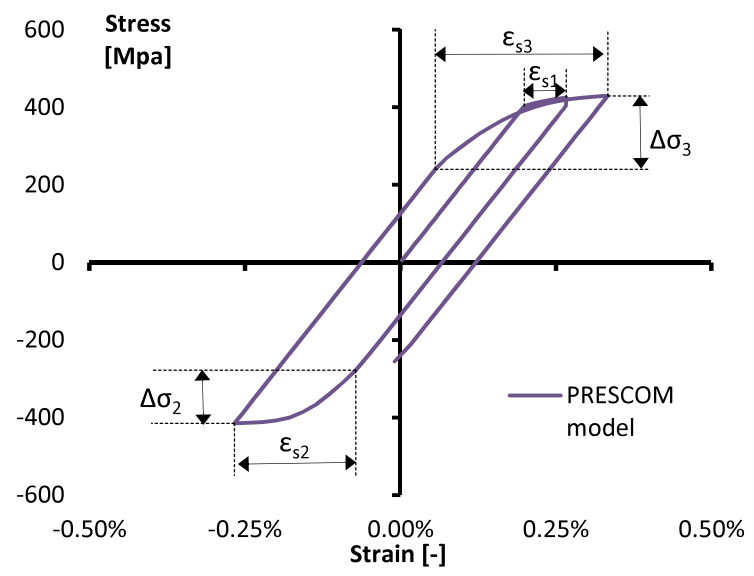

Fig. 11. Illustration of hardening behaviour by the Chaboche model 
ship, while the effect of the fourth and the fifth formulas have relatively small effect in small plastic strain range; these have effects only on the behaviour at larger strain level.

The translation of the yield surface can be expressed as a function of the accumulated plastic strain at each FrederickArmstrong formula:

$$
\frac{\Delta \sigma_{i}}{2}=\frac{C_{i}}{\gamma_{i}} \tanh \left(\gamma_{i} \frac{\Delta \varepsilon_{p l}}{2}\right) \quad \text { where } \quad \gamma_{i} \frac{\Delta \varepsilon_{p l}}{2}=\beta
$$

where $C_{i}, \gamma_{i}$ are material model constants, $\Delta \varepsilon_{\mathrm{pl}}$ is the accumulated plastic strain increment. The $\beta$ in Eq. (17) controls the saturation rate of the hardening; if $\beta$ reaches 2.5 , the hardening is saturated by $99 \%$.

In the transitional range of plastic strain the first three Frederick-Armstrong formulas are dominant; updating parameters of the other formulas are negligible, as shown Model 4 in Fig. 12 The main goal of the dynamic parameter calculation in the PRESCOM model is the accurate description of the transitional steel behaviour. In this state as the relevant plastic strain increases, the yielding surface decreases, and in parallel the hardening increases, as it seen in Fig. 11. (as the strain amplitude increase $\left(\varepsilon_{\mathrm{s} 3}>\varepsilon_{\mathrm{s} 2}\right)$ the yielding surface decrease, while the kinematic hardening increase $\left.\left(\Delta \sigma_{3}<\Delta \sigma_{2}\right)\right)$.

In the transitional state it is important to reach the yielding stress at the previously experienced maximum strain level regardless the decrease of yielding surface. This hardening (between the virgin and the saturated behaviour) is reproduced by the first Frederick-Armstrong formula. Although the yield stress is constant $\left(f_{\mathrm{y}, \text { num }}\right)$ in the transitional parameter set, yielding seems to occur at a higher stress level than $f_{\mathrm{y}, \text { num }}$ if large initial hardening parameter is used (Model 1 in Fig. 12, or $\varepsilon_{\text {REL }}=0.5 \%$; $\varepsilon_{\text {REL }}=1 \%$ in Fig. 13/a). The decrease of initial hardening modulus leads to the decrease of this virtual yield surface.

The parameters of the first formula can be updated as:

$$
\gamma_{1}=\frac{\beta}{\varepsilon_{R P L}} \quad \text { and } \quad C_{1}=\gamma_{1} \sigma_{\Delta}
$$

where $\varepsilon_{R P L}$ is the relevant von Mises strain, and $\sigma_{\Delta}$ takes the cyclic degradation of the yield stress into account. Using appropriate $\beta$ value in Eq. (18), the $\gamma_{1}$ value ensures the follows: the hardening from the decreased yielding surface $\left(f_{y, \text { nит }}\right)$ to the stress level of the plateau $\left(f_{y, \text { real }}\right)$ occurs at the appropriate strain value. Therefore the first formula always produces the same shifting of loading surface, the hardening, however, saturates by the relevant plastic strain. The smaller the maximal strain amplitude of the previous loading, the larger the parameters of the first model will be, ensuring that yielding plateau is reached at the relevant strain amplitude.

The second and third models describe the hardening during the saturation of the Bauschinger effect $\left(\varepsilon_{\mathrm{REL}}=1,2,3,6 \%\right.$, on Fig. 13/a). The experimental results show that, the cyclic hardening of the steel in the transitional zone hardly larger than the yielding stress. Therefore the initial hardening parameters of the second and third formulas are less than in the cyclic set. The transition to cyclic state is described by a polynomial function, given in Eq. (19). At the end of the transitional range, the behaviour by the transitional parameters is the same as the behaviour with the cyclic parameter set, the parameters of transitional set is calculated by the cyclic parameter values.

$$
C_{i}=\left(\frac{\varepsilon_{R P L}}{\varepsilon_{E Q W 2}}\right)^{\alpha} C_{i}^{c}
$$

where $i=2$ or 3 and $\alpha=1.5$.

The stress level at a given strain rate depends on the loading history and this results in different stress values for the same strain level (see Fig. 10). The decrease of the hardening of second and third formulas in the transitional set, however, affects the hardening behaviour of model at larger strain level. Using smaller hardening, according to Eq. 19, produces too small hardening at larger strain level. Therefore the $C$ parameter of the fifth formula is modified in order to offset the second and third formulas effect at large strain rate as detailed in Eq. 20].

$$
C_{5}=C_{5}^{c}\left(\alpha_{L}-\left(\alpha_{L}-1\right)\left(\frac{\varepsilon_{R P L}}{\varepsilon_{E Q W 2}}\right)^{\alpha}\right)
$$

where $\alpha_{\mathrm{L}}=5$ and $\alpha=1.5$.

As a result of this procedure PRESCOM model can follow the steel behaviour at small range of plastic strain, can consider the effect of the preloading, too. Fig. 13, b shows the pure virgin and cyclic behaviour.

\subsection{Model parameter calibration}

Model parameters are determined by the "Trial and error method" using the experimental results of Youngjiu et. al. [5] as the basis of calibration. In this paper the results of the model calibration of Q345B specimens are presented. The numerical model is a simply supported, cuboid solid element (Fig. 14), that can describe the material behaviour without the influence of element geometry. The calibrated parameters are shown in Table 7 , the static parameter set is equal to the static set of MISO model, as detailed in Table 6

Parameters of the transitional Chaboche models are calculated from the cyclic parameter set by three constants: $\alpha, \alpha_{\mathrm{L}}, \beta$; for the calibration the experimental results of [5,7] are used. The $\beta$ parameter influences the curvature of the stress-strain curve at small plastic strain levels. $\beta=2.5$ approximates the experimental result appropriately, as shown in Fig. 15. The futher parameters of the hardening according to Eqs. (19) and 20) are determined as $\alpha=1.5$ and $\alpha_{\mathrm{L}}=5.0$. 


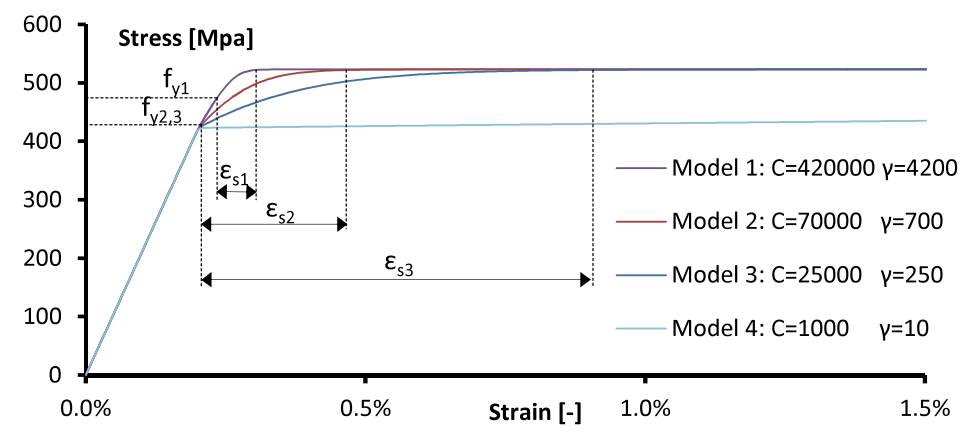

Fig. 12. Illustration of hardening behaviour modeled by Frederic-Armstrong formulas
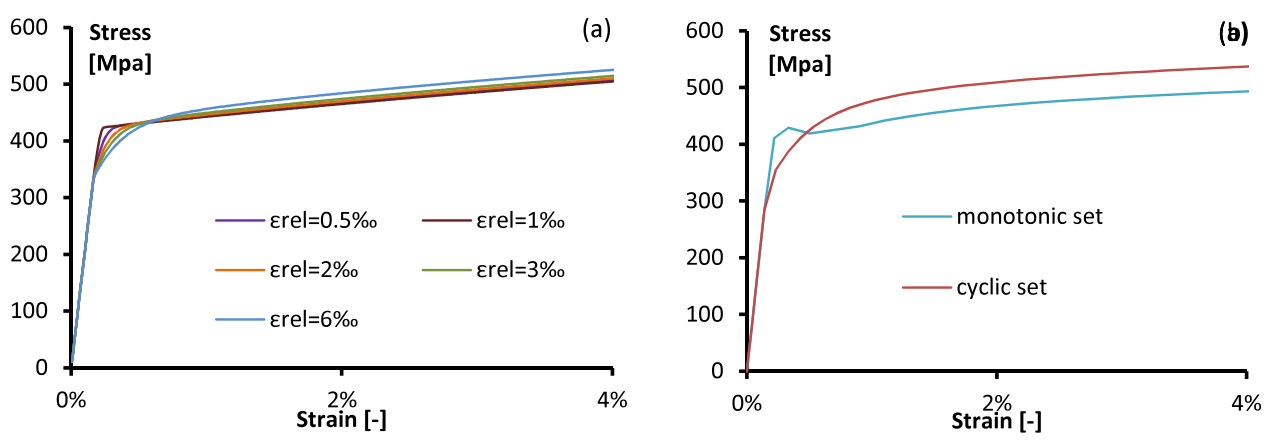

Fig. 13. The results of PRESCOM model under monotonic loading calibrated by steel material Q435 [5]: in the function of maximal relevant plastic strain experienced in preloading (a); pure virgin (monotonic set) and cyclic (cyclic set) material behaviour (b)

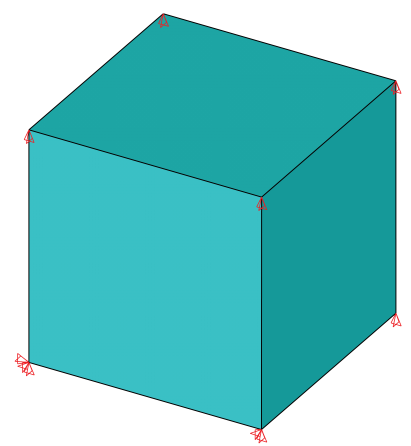

Fig. 14. Numerical FEM model for testing material model

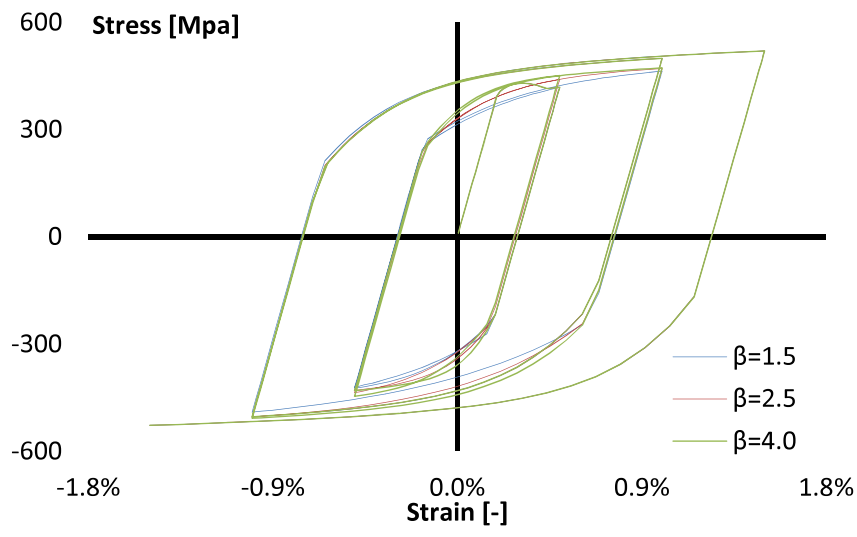

Fig. 15. Results of the PRESCOM model in the function of $\beta$ parameter in the small range of plastic strain 
Tab. 7. Parameters of PRESCOM model

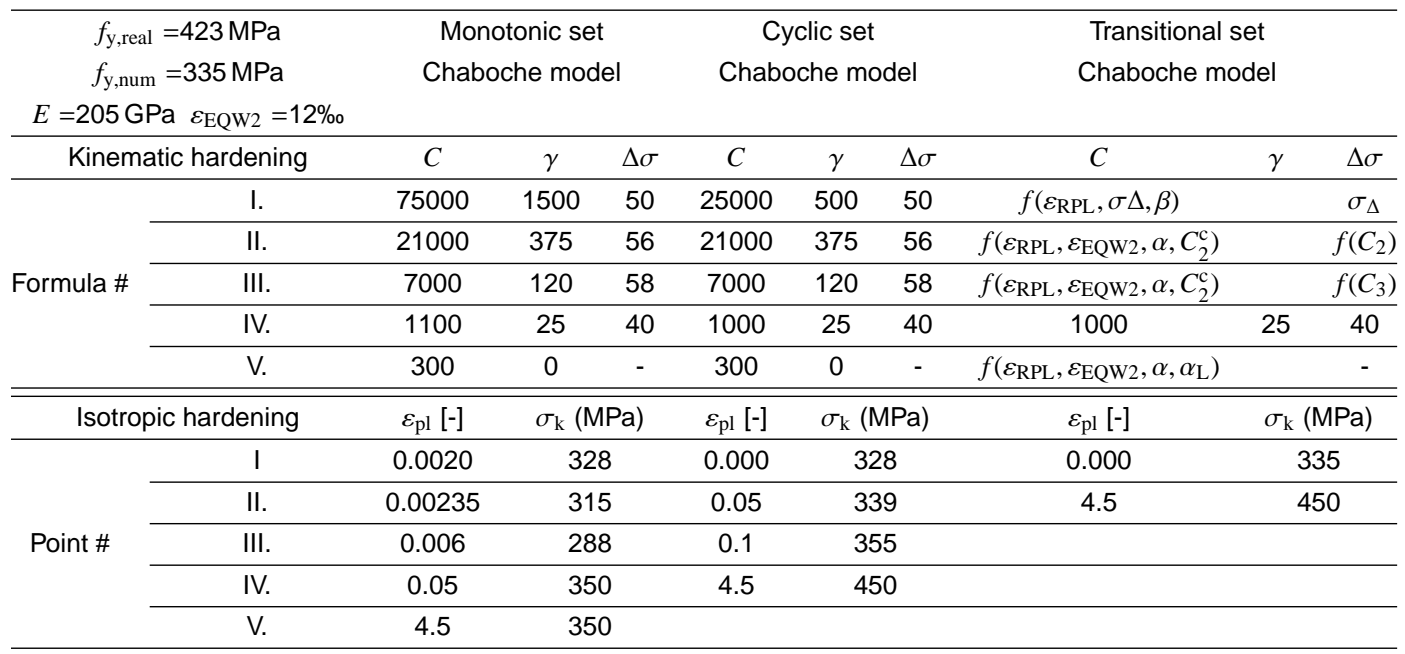

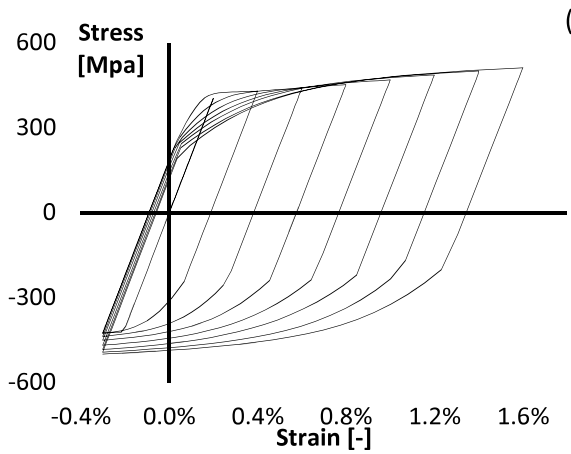

(a)

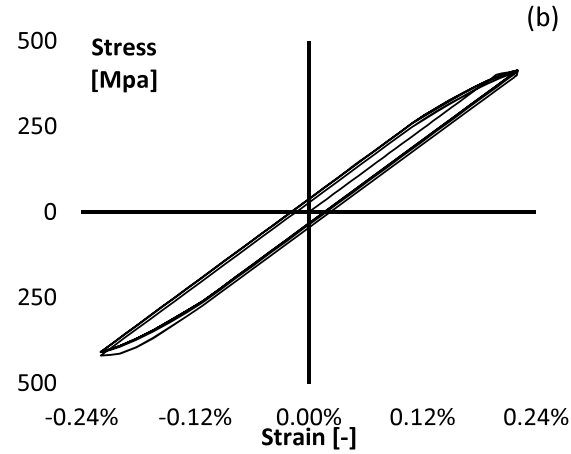

Fig. 16. Transition of the yielding plateau and decrease of the yielding stress under non proportional loading (a) ; and cyclic behaviour in the transitional plastic strain range (b)
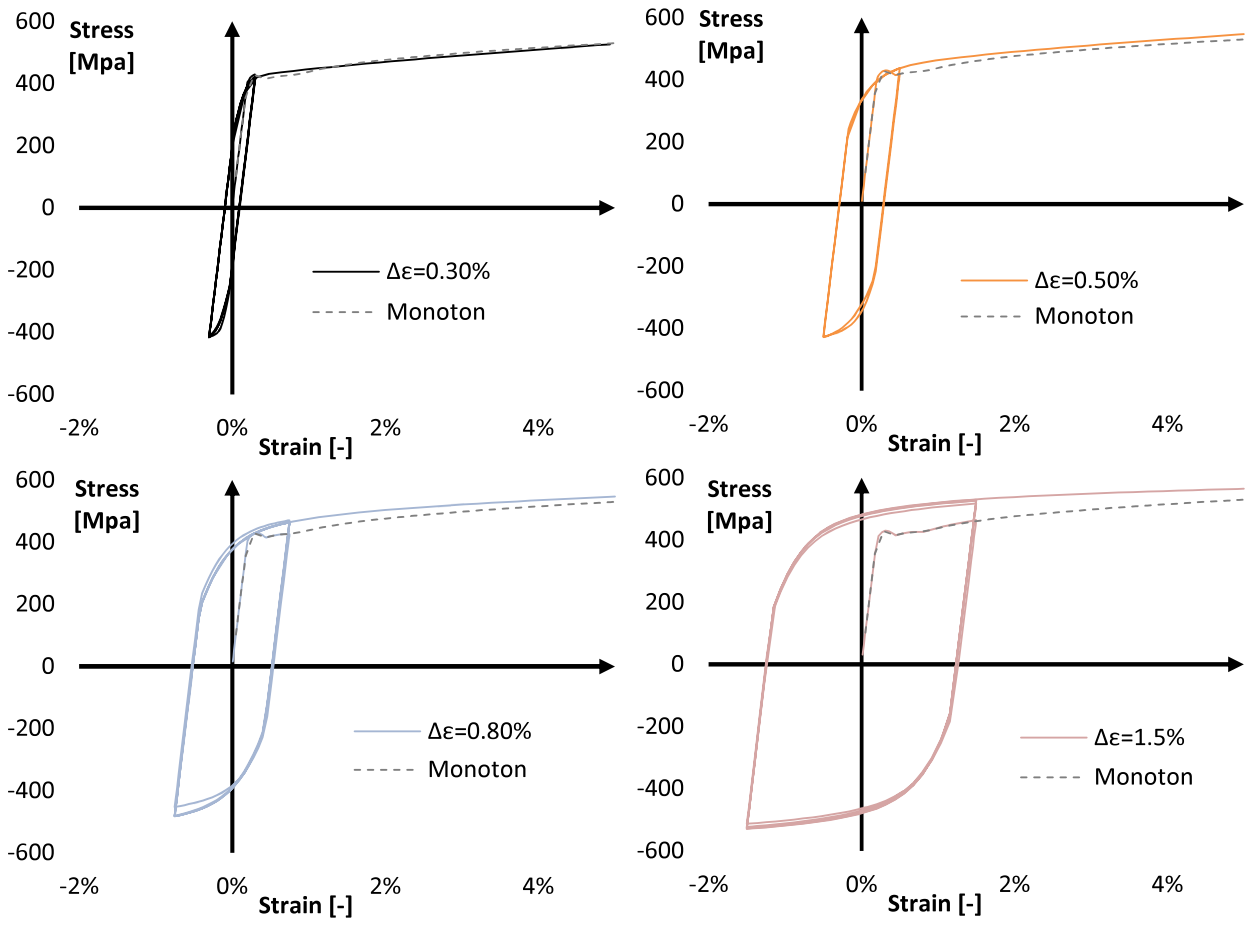

Fig. 17. Effect of preloading on small amplitude of plastic strain 
5.4 Monotonic, saturated, ratcheting and cyclic behaviour

The above detailed procedure results in a model that can describe the saturation of Bauschinger effect and the decrease of yield surface. Fig. 13 shows the model behaviour under monotonic loading, with and without previous loading. The dynamic updating of parameters allows to describe the transition between the two stages. The initial hardening parameter of the first Chaboche model decreases in the function of previous loading causing lower virtual yield surface; and the $\mathrm{C}$ value of the second and third models increases, causing additional hardening.

The decrease of stress observed by the MISO model at small amplitude of cyclic loading (see Fig. 8) does not occur by this model, and saturation under low strain cyclic loading is described properly (Fig. 16). (In this case the small amplitude of loading means the loading which cause smaller plastic strains than the necessary plasticity for saturation Bauschinger effect.)

Fig. 17 shows the effect of the preloading on small amplitude of plastic strain. If the preloading is relative small, the steel behaviour hardly differs from monotonic case $(\Delta \varepsilon=0.3 \%)$. By the increasing amplitude of preloading, however, the behaviour gradually becomes cyclic.

The decrease of yielding surface is shown in Fig. 18 The elastic part of the stress-strain curve becomes smaller, as the amplitude of plastic strain raises. Fig. 18 shows the inaccuracy of PRESCOM model. During monotonic loading if the material is given plastic loading and the loading direction turns into opposite direction but it remains in the elastic range (Fig. 18/a), the behaviour of the material stays monotonic (there are not plasticity in the opposite direction). However the parameter refreshing is calculated if the unloading occurs (if the inner point of yield surface is reached). Therefore the behaviour of material can be switched to cyclic even if the next load direction remains elastic and the behaviour of material also remains monotonic or transitional.

If the state variable of the material is maximum value of strain range $\left(\varepsilon_{R P L}=q\right)$ the result of the material model is shown on Fig. 19. If the amplitude of $q$ stays small and the reloading remains elastic range the steel is described better, nevertheless this inaccuracy can occur whit this state variable as the unloading occurs at higher strain level (the relevant plastic strain raises).

Fig. 20 shows ratcheting behaviour results of the PRESCOM model. In Fig. 20/a the mean stress is $\sigma_{x m}=40 \mathrm{MPa}$ with $\sigma_{x a}=$ $420 \mathrm{MPa}$ fluctuations, and in Fig. 20 $\mathrm{b}$ these values are: $\sigma_{x m}=$ $-15 \mathrm{MPa}$ and $\sigma_{x a}=440 \mathrm{MPa}$. Although the PRESCOM model can describe the ratcheting phenomenon of the steel, the results slightly overestimate the experimental values [24,25].

The used state variable influences the ratcheting phenomenon calculated by the PRESCOM model. In Fig. 21/ a $\varepsilon_{R E L}$ is calculated by Eq. 15,; in this case the increase of maximal plastic strain cause the change of hardening conditions in PRESCOM model, therefore the curves becomes wider and more energy dissipation, as it can be observed in the test results of [25]. In
Fig. 21) b the state variable is $q$; although the plastic strain increases, the difference of accumulated plastic strain between two load direction hardly differs, therefore the hardening behaviour of PRESCOM model remains the same, and does not occur the decrease of the yielding surface. This produces very narrow hysteretic loops, and less energy dissipation.

According to the model behaviour under elastic unloadingreloading and non-proportional ratcheting, the following conclusions can be done:

1 Using maximum value of strain range (q) as state variable produces more accurate behaviour, if the elastic unloading and reloading occurs, although if the elastic unloading appears on high strain level at first, the accuracy decrease, because the cyclic parameter set is activated.

2 In the case of ratcheting simulations the decrease of yielding surface cannot be formed in some loading conditions if the state variable is q. If the model uses the relevant plastic strain (Eq. 15) as state variable (Figs. 9, 18, 19, 21), it fits best to most of the loading conditions.

The results of the application of PRESCOM material model under different cyclic loading are shown in Fig. 22 together with the experimental data. The obtained results are properly accurate, especially at the tension side of the hardening. In case of compression the calculated curves show higher values than the experimental tests.

\section{Conclusion}

The paper focuses on the modeling of the cyclic behaviour of conventional steel material. The main propose of the research is to develop an efficient material model which is sufficiently accurate and can be implemened in a finite element program, such as ANSYS, for high precision numerical calculations. The paper presents some Chaboche base material model, and a comparative analysis of steel material models of different efficiency and accuracy under cyclic loading in ANSYS environment. Three basis cyclic material models (bilinear, multi-linear, Chaboche) and three developed Chaboche-based material models are presented (NLISO, MISO, PRESCOM). Although the models are developed in the ANSYS finite element environment, the procedure can be adopted in other software, where the Chaboche model is available and they can be combinational. During the research the following results are occurred:

- Three Chaboche-based material models are developed, the most accurate material model is the Parameter refreshed and strain controlled combined Chaboche model with isotropic hardening (PRESCOM model).

- The implemented parameter refreshing calculation method makes the model possible to follow accurately the steel behaviour for the whole range of cyclic loading, particularly at the transitional phase. 


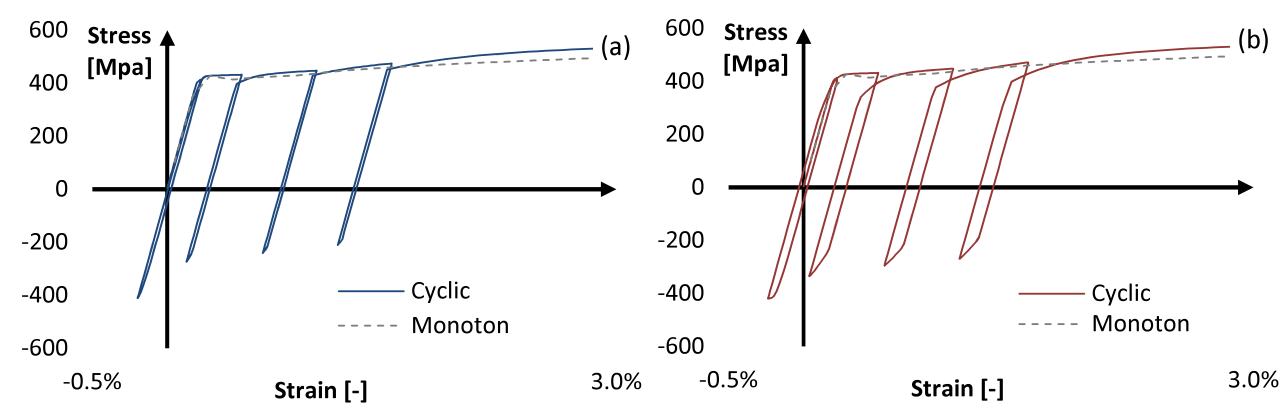

Fig. 18. Monotonic behaviour of PRESCOM model under under elastic unloading (a); under small amplitude of plastic unloading (b)

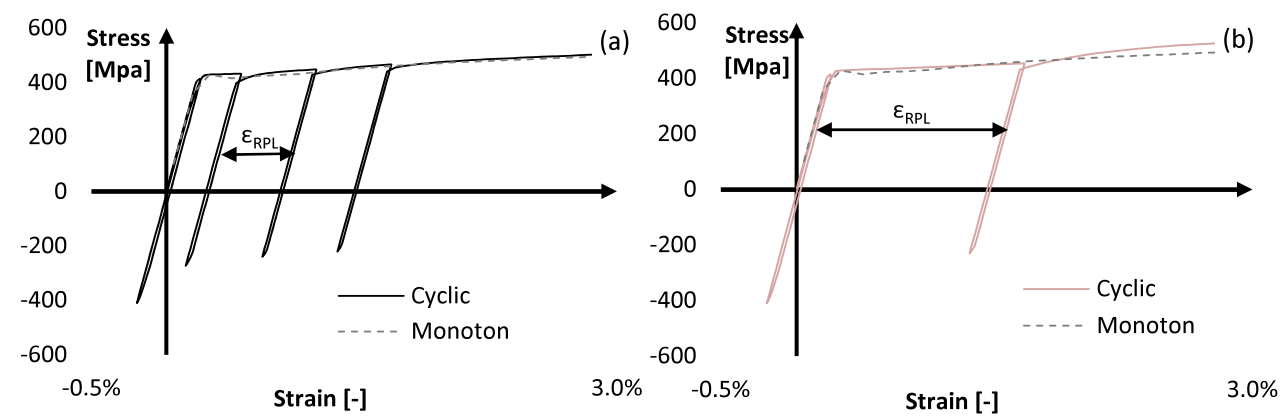

Fig. 19. Monotonic behaviour of PRESCOM with $\varepsilon_{\mathbf{R P L}}=q$ model under elastic unloading (a) under small amplitude of plastic unloading (b)

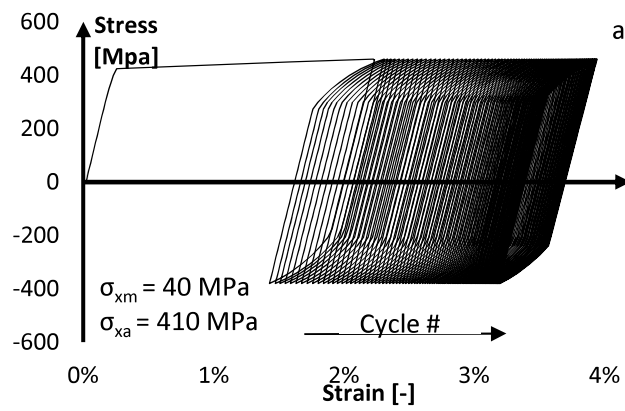

a) 600 Stress

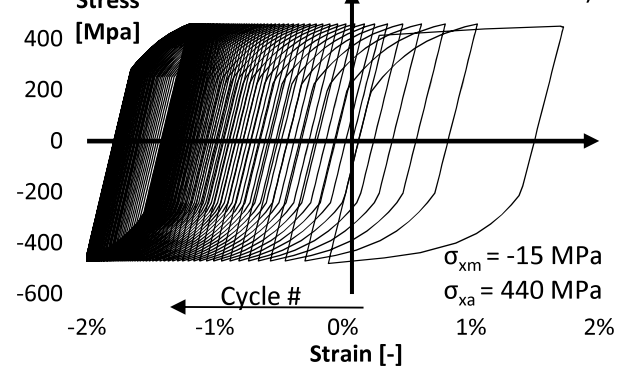

Fig. 20. Ratcheting behaviour results of PRESCOM model

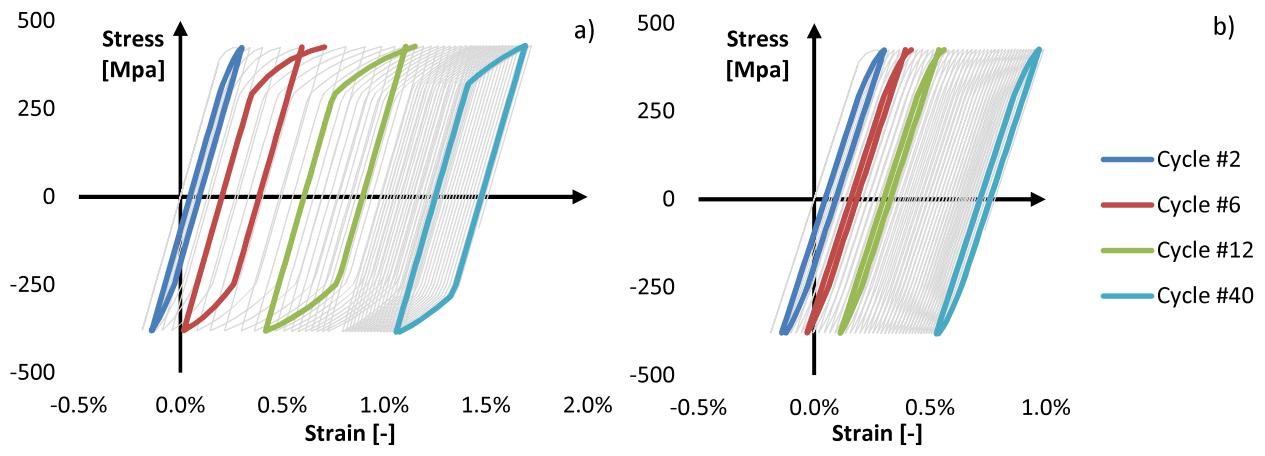

Fig. 21. Racheting behaviour calculated by the PRESCOM model with different state variable: a): $\varepsilon_{\mathrm{RPL}}=\max \left(\varepsilon_{\mathrm{pl}, \mathrm{MAX}}, q\right)$ and b): $\varepsilon_{\mathrm{RPL}}=q$ 

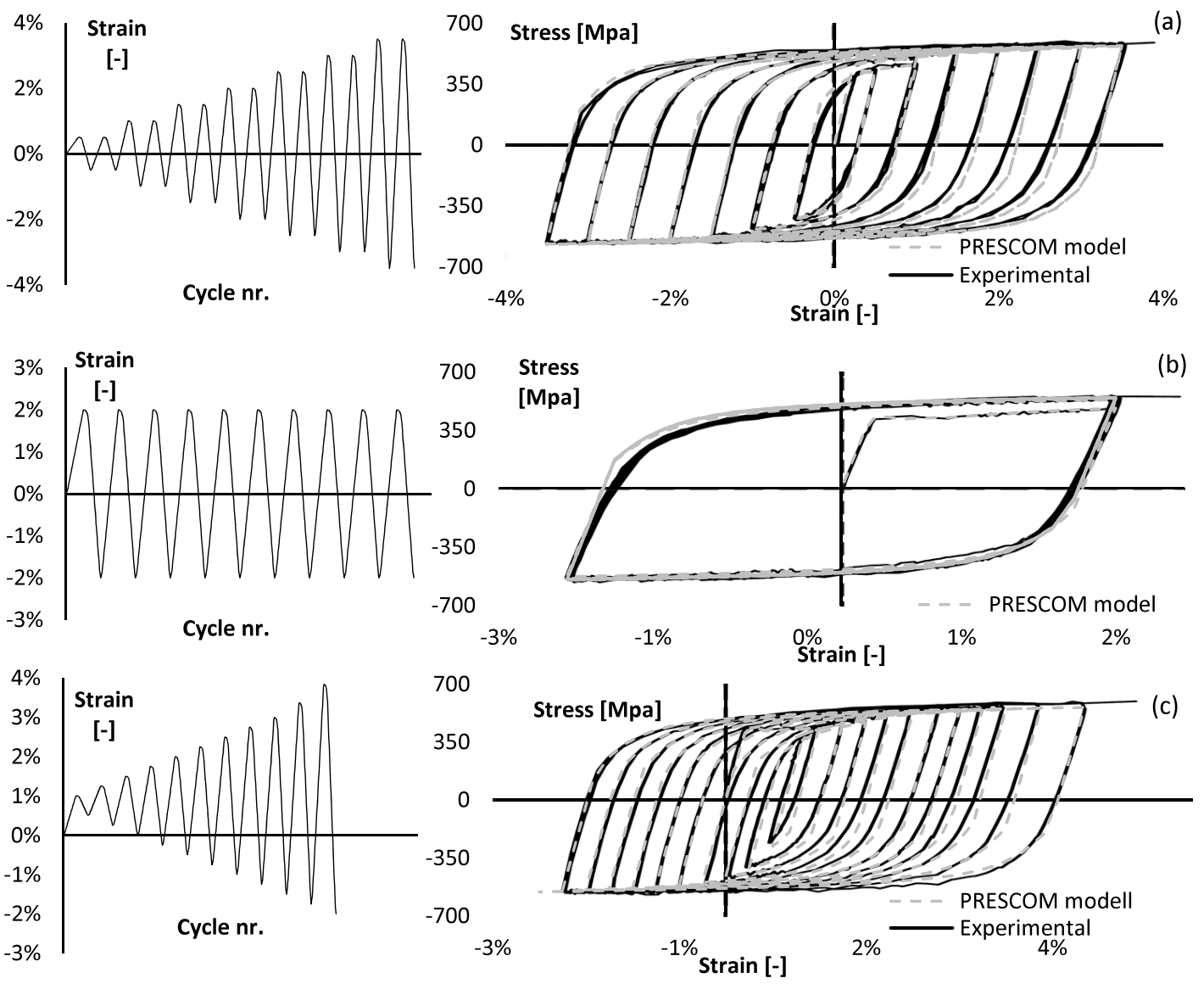

[Mpa]

(b)
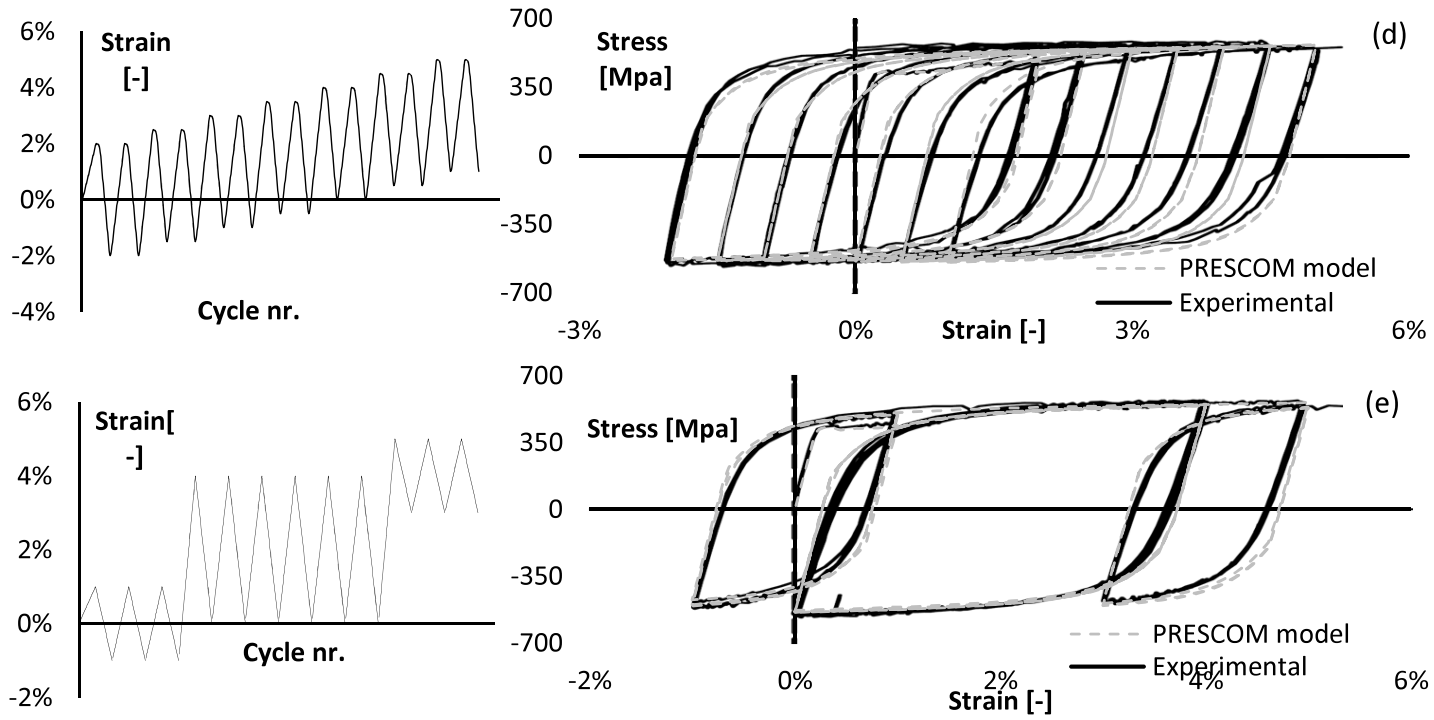

Fig. 22. Comparison of the PRESCOM model and test results for different cyclic loading histories: (a) proportionally increased amplitudes of loading; (b) constant proportional loading; (c) non-proportionally increased amplitudes of loading; (d) non-proportionally increased loading with constant amplitudes; (e) non-proportionally increased loading with various amplitudes 
- The developed material model can describe both monotonic and cyclic behaviour, the disappearance of the yielding plateau, the saturation of the Bauschinger effect, the ratcheting effect and the load history dependence.

- The material model is calibrated on the basis of uniaxial experimental results. The accuracy of the numerical model is verified by several load paths. The developed material model is proved to be accurate and it can be applied in nonlinear time history, and cyclic geometrical and material nonlinear imperfect analyses.

\section{Acknowledgment}

The work reported in the paper has been developed in the framework of the project "Talent care and cultivation in the scientific workshops of BME" project. This project is supported by the grant TÁMOP-4.2.2.B-10/1-2010-0009. The authors would also like to express their gratitude to Tsinghua University, Department of Civil Engineering for the steel material laboratory test results.

\section{References}

1 ANSYS Release 11.0 Documentation, Theory reference for ANSYS and ANSYS workbench11, Ansys Inc.; USA, 2007.

2 Budaházy V, Dunai L, Steel material model development for cyclic analysis, 6th European Conference on Steel and Composite Structures, In: Dunai L, Iványi M, Kovács N, Vigh LG (eds.), 6th European Conference on Steel and Composite Structures, ECCS European Convention for Constructional Steel Research; Budapest, Hungary, 2011, pp. 1106-1111. Vol. B, ISBN: 978-92-9147-103-4.

3 Jiang Y, Zhang J, Benchmark experiments and characteristic cyclic plasticity deformation, International Journal of Plasticity, 24, (2008), 1481-1515, DOI doi:10.1016/j.ijplas.2007.10.003.

4 Beer FP, Jr. Johnston ER, Dewolf TJ, Mazurek DF, Mechanics of Materials, McGraw-Hill Companies; New York, USA, 2009, ISBN ISBN 978-007-352938-7.

5 Youngjiu S, Meng W, Yuanqing W, Experimental and constitutive model study of structural steel under cyclic loading, Journal of Constructional Steel Research, 67, (2011), 1185-1197, DOI doi:10.1016/j.jcsr.2011.02.011.

6 Dusicka P, Itani AM, Buckle IG, Cyclic response of plate steel under large inelastic strains, Journal of Constructional Steel Research, 63, (2007), 156164, DOI doi:10.1016/j.jcsr.2006.03.006.

7 Lee G, Chang KC, The experimental basis of material constitutive laws of structural steel under cyclic and nonproportional loading, Stability and Ductility of Steel Structures under Cyclic Loading, In: Fukumoto Y, Lee GC (eds.), Stability and Ductility of Steel Structures under Cyclic Loading, CRC Press; Osaka, Japan, 2000, pp. 3-14. ISBN-13: 978-0849301445.

$8 \mathbf{M r o z} \mathbf{Z}$, An attempt to describe the behaviour of metals under cyclic loads using more general work hardening model, Acta Mechanica, 7, (1969), 199212, DOI doi:10.1007/BF01176668.

9 Krieg RD, A practical two surface plasticity theory, Acta Mechanica, 42, (1975), 641-647, DOI doi:10.1115/1.3424656.

10 Petersson N, Popov EP, Constitutive relations for generalized loadings, Journal of the Engineering Mechanics Division, 103, (1977), 611-627, DOI doi:10.1520/JTE12170J.

11 Dafalias YF, Popov EP, A model of nonlinearly hardening material for complex loading, Acta Mechanica, 21, (1975), 173-192, DOI doi:10.1007/BF01181053.
12 Chaboche JL, Dang-Van K, Cordier G, Modelization of strain memory effect on the cyclic hardening of 316 stainless steel, International Conference on SMiRT, ( Berlin, Germany), In: Okadome T, Jamazaki T, Makhtari M (eds.), Stability and Ductility of Steel Structures under Cyclic Loading, 2000, pp. 3-14. ISBN-13: 978-0849301445.

13 Armstrong PJ, Frederick CO, A mathematical representation of the multiaxial Bauschinger effect, Central Electricity Generating Board; Berkeley, UK, 1966, DOI 10.3184/096034007X207589. Report RD/B/N731.

14 Chaboche JL, Mehanics of Solid Materials, Cambridge University Press, 1990, ISBN ISBN 978-0521477581.

15 Imaoka S, Chaboche Nonlinear Kinematic Hardening Model, 2008. Memo number: STI0805A.

16 Chaboche JL, Rousselier G, On the plastic and viscoplastic constitutive equations, Parts I and II, Journal of Pressure Vessel and Piping, 105, (1983), 453-164.

17 Marquis D, Etude théorique et vérification expérimentale d'un modéle de plasticité cyclique, Thesis, Université Pierre et Marie Curie, 1979.

18 Watanabe $\mathbf{O}$, Atluri SN, Constitutive modeling of cyclic plasticity and creep, using an internal time concept, International Journal of Plasticity, 2, (1986), 107-134, DOI doi:10.1016/0749-6419(86)90008-2.

19 Chaboche $\mathrm{JL}$, A review of some plasticity and viscoplasticity constitutive theories, International Journal of Plasticity, 24, (2008), 1642-1693, DOI doi:10.1016/j.ijplas.2008.03.009.

20 Besseling JF, A theory of elastic, plastic, and creep deformation of an initially isotropic material showing anisotropic strain-hardening, creep recovery, and secondary creep, Journal of Applied Mechanics, 17, (1958), 529536, DOI doe:AF49(638)-223.

21 Owen RJ, Prakash A, Zienkiewicz OC, Finite element analysis of nonlinear composite materials by use of overlay system, Computers and Structures, 4, (1974), 1251-1267, DOI 10.1016/0045-7949(74)90035-2.

22 Voce E, A Practical strain hardening function, Metallurgia, 51, (1955), 219226.

23 Budaházy V, Cyclic analysis of steel bolted joints (in Hungarian), MSc Thesis, Budapest University of Technology and Economics, Department of Structural Engineering, 2010.

24 Krishna S, Hassan T, Naceur IB, Sai K, Cailletaud G, Macro versus micro-scale constitutive models in simulating proportional and nonproportional cyclic and ratcheting response of stainless steel 304, International Journal of Plasticity, 25, (2009), 1910-1949, DOI 10.1016/j.ijplas.2008.12.009.

25 Kang A, Li Y, Gao Q, Non-proportionally multiaxial ratcheting of cyclic hardening materials at elevated temperatures; experiment and simulations, Mechanics of Materials, 37, (2005), 1101-1118, DOI 10.1016/j.mechmat.2005.01.006.

26 Xianjie Yang $\mathbf{X}$, Low cycle fatigue and cyclic stress racheting failure behaviour of carbon steel 45 under uniaxial cyclic loading, International Journal of Fatigue, 27, (2005), 1124-1132, DOI 10.1016/j.ijfatigue.2005.01.004. 